\section{Case Reports in Gastroenterology}

Case Rep Gastroenterol 2020;14:436-442

DOI: 10.1159/000510161

Published online: August 26, 2020

(C) 2020 The Author(s)

Published by S. Karger AG, Basel

www.karger.com/crg

This article is licensed under the Creative Commons Attribution-NonCommercial 4.0 International License (CC BY-NC) (http://www.karger.com/Services/OpenAccessLicense). Usage and distribution for commercial purposes requires written permission.

\title{
Infected Pancreatic Necrosis Mimicking Pancreatic Cancer
}

\author{
Jun $\mathrm{HeO}^{\mathrm{a}, \mathrm{b}}$ \\ aDepartment of Internal Medicine, Kyungpook National University Hospital, \\ Daegu, Republic of Korea; 'bShool of Medicine, Kyungpook National University, \\ Daegu, Republic of Korea
}

\section{Keywords}

Pancreatitis · Pancreatic cancer · Endoscopic ultrasonography

\begin{abstract}
Although infected pancreatic necrosis can develop as a result of rare conditions involving trauma, surgery, and systemic infection with an uncommon pathogen, it usually occurs as a complication of pancreatitis. Early phase of acute pancreatitis can be either edematous interstitial pancreatitis or necrotizing pancreatitis. The late complications of pancreatitis can be divided into pancreatic pseudocyst due to edematous interstitial pancreatitis or walled-off necrosis due to necrotizing pancreatitis. During any time course of pancreatitis, bacteremia can provoke infection inside or outside the pancreas. The patients with infected pancreatic necrosis may have fever, chills, and abdominal pain as inflammatory symptoms. These specific clinical presentations can differentiate infected pancreatic necrosis from other pancreatic diseases. Herein, I report an atypical case of infected pancreatic necrosis in which abdominal pain, elevation of white blood cell, and fever were not found at the time of admission. Rather, a $10-\mathrm{kg}$ weight loss (from 81 to $71 \mathrm{~kg}$ ) over 2 months nearly led to a misdiagnosis of pancreatic cancer. The patient was finally diagnosed based on endoscopic ultrasound-guided fine-needle aspiration. This case highlights that awareness of the natural course of pancreatitis and infected
\end{abstract}




\section{Case Reports in Gastroenterology}

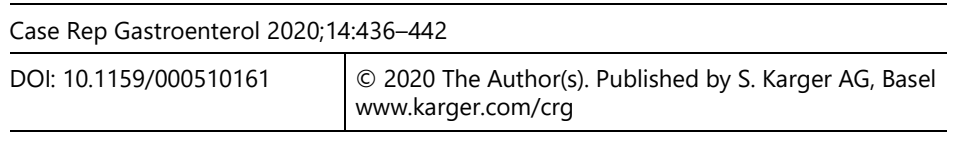

Heo: Infected Pancreatic Necrosis Mimicking Pancreatic Cancer

pancreatic necrosis is important. In addition, endoscopic ultrasound-guided fine-needle aspiration should be recommended for the diagnosis and treatment of indeterminate pancreatic lesions in selected patients.

(C) 2020 The Author(s)

Published by S. Karger AG, Basel

\section{Introduction}

Pancreatic mass-forming, inflammatory, benign lesions can masquerade as pancreatic cancer. These cases include pancreatic tuberculosis, autoimmune pancreatitis, eosinophilic pancreatitis, and infected pancreatic necrosis [1]. Among them, infected pancreatic necrosis is a kind of complication of pancreatitis. It usually requires treatment with antibiotics and/or drainage. Most patients with infected pancreatic necrosis complain of abdominal pain, fever, chills, nausea, and leukocytosis. These specific clinical presentations can differentiate infected pancreatic necrosis from other pancreatic diseases. However, when we meet this infected pancreatic necrosis at a specific time of the pancreatitis course at which no infectious symptoms/sign are present, an infected wall-off pancreatic necrosis might be misdiagnosed as a pancreatic malignancy. Herein, I present a case of infected pancreatic necrosis mimicking malignancy.

\section{Case Presentation}

A 67-year-old male was referred from a local medical center and admitted to our hospital for body weight loss of approximately $10 \mathrm{~kg}$ over 2 months (from 81 to $71 \mathrm{~kg}$ ). He denied fever or chills and had no abdominal pain. Abdominal computed tomography (CT) performed at a local medical center showed a $53 \times 39 \mathrm{~mm}$, exophytic low-density mass in the uncinate process of the pancreas (Fig. 1a) and a $19 \times 14 \mathrm{~mm}$, low-density mass in the body of the pancreas (Fig. 1b). The patient was taking medication for hypertension and type 2 diabetes mellitus. He reported consuming one bottle of an alcoholic beverage per day and had never smoked. Vital signs were as follows: blood pressure $110 / 65 \mathrm{~mm} \mathrm{Hg}$, pulse rate $77 / \mathrm{min}$, respiratory rate $18 / \mathrm{min}$, and body temperature $36.4^{\circ} \mathrm{C}$. On physical examination, the patient appeared to have anicteric sclera, and his abdomen was soft and flat without tenderness. The laboratory findings were as follows: white blood cell count 7,060/ $\mu \mathrm{L}$ (neutrophil 69.3\%) , hemoglobin 12.3 $\mathrm{g} / \mathrm{dL}$, platelet count $300,000 / \mu \mathrm{L}$, aspartic acid aminotransferase $14 \mathrm{IU} / \mathrm{L}$, alanine aminotransferase $17 \mathrm{IU} / \mathrm{L}$, blood urea nitrogen $12.4 \mathrm{mg} / \mathrm{dL}$, creatinine $0.79 \mathrm{mg} / \mathrm{dL}$, C-reactive protein $2.62 \mathrm{mg} / \mathrm{dL}$, carcinoembryonic antigen $5.9 \mathrm{ng} / \mathrm{mL}$, carbohydrate antigen 19-9 $48.35 \mathrm{U} / \mathrm{mL}$, fasting serum glucose $367 \mathrm{mg} / \mathrm{dL}$, and hemoglobin A1c 11.6\%.

Since pancreatic cancer was suspected, the patient was evaluated for surgical treatment based on the CT findings. The mass in the pancreatic body seemed to abut the superior mesenteric artery. On the day after admission, magnetic resonance imaging (MRI) was performed to further characterize the pancreatic lesion. The interval between the MRI and the previous CT was 21 days. On MRI, the mass in the uncinate process decreased from 53 to $35 \mathrm{~mm}$, while the mass in the body increased from $19 \mathrm{~mm}$ to $40 \mathrm{~mm}$ (Fig. 2). Based on the MRI findings, we predicted that the pancreatic lesions are atypical inflammations, such as tuberculosis. 


\section{Case Reports in Gastroenterology}

\begin{tabular}{l|l}
\hline Case Rep Gastroenterol 2020;14:436-442 \\
\hline DOI: 10.1159/000510161 & $\begin{array}{l}\text { @ 2020 The Author(s). Published by S. Karger AG, Basel } \\
\text { www.karger.com/crg }\end{array}$ \\
\hline
\end{tabular}

Heo: Infected Pancreatic Necrosis Mimicking Pancreatic Cancer

Endoscopic ultrasound-guided fine-needle aspiration (EUS-FNA) was planned to differentiate this atypical inflammatory lesion. On the 6th day of hospitalization, one day prior to EUS-FNA, the patient developed a fever of $37.9^{\circ} \mathrm{C}$ and was treated with intravenous third-generation cephalosporin. The next day, EUS-FNA (GF-UCT 260; Olympus Co., Tokyo, Japan, and 22-gauge needle, Mediglobe; Mediglobe Co., Achenmuehle, Germany) was performed according to our previous plan. The mass of the body of the pancreas was irregular in shape, and the margin was unclear; moreover, a low echoic lesion was identified in the center. Pus-like fluid was aspirated from the tissue by EUS-FNA. However, the abscess of the pancreatic body lesion was ruptured to the peripancreatic area just after EUS-FNA. The EUS-FNA procedure was aborted, and the patient was closely monitored in the ward. The aspirated fluid was not sent for culture sensitivity. Later, a cytological examination only revealed the presence of inflammatory cells within the pancreas parenchyma (Fig. 3). Fever had subsided after 4 days of intravenous antibiotic treatment. After treatment with intravenous antibiotics for 11 days, the patient was discharged with per-oral antibiotics for 7 days. After 1 month, the follow-up abdominal CT demonstrated that the mass in the uncinate process decreased to $8 \mathrm{~mm}$, and the mass in the body was no longer present. The patient has been compliant and has continued with follow-up as of now.

\section{Discussion}

According to the revised 2012 Atlanta classification of acute pancreatitis, the early phase of acute pancreatitis can be either edematous interstitial pancreatitis or necrotizing pancreatitis. The late complications of pancreatitis can be divided into pancreatic pseudocyst due to edematous interstitial pancreatitis or walled-off necrosis due to necrotizing pancreatitis. These late complications usually develop approximately 4 weeks after the onset of acute pancreatitis [2]. During any time course of pancreatitis, bacteremia can provoke infection inside or outside the pancreas. Patients with infected pancreatic necrosis usually complain of fever/chills and present with an increased white blood cell count. However, in this case, leukocytosis and fever were not found at the time of admission. Meanwhile, a 10-kg weight loss over 2 months, which was the result from poorly controlled diabetes, led to a misdiagnosis as pancreatic cancer. Immediately after FNA, the detailed medical history of the patient revealed that severe epigastric pain had persisted for several days at 6 weeks prior to admission. Therefore, in the case of pancreatic masses, it is important to identify the history and specific symptoms of pancreatitis in order to rule out pancreatitis-related inflammatory lesions.

External wall formation, a septum, or liquid-liquid interface can be observed inside the infected pancreatic necrosis. The characteristics and morphology of an abscess can change according to the degree of maturity. In the very early stages of infected pancreatic necrosis, the focal pancreatitis can appear as an acutely inflamed area without wall formation. Depending on the imaging modality, both pancreatic cancer and the early stage of infected pancreatic necrosis have the same features, which are as follows: hypoechoic appearance on ultrasonography, hypodense appearance on CT, low-signal intensity on a T1-weighted image by MRI, and high-signal intensity on a T2-weighted image by MRI. Moreover, some focal pancreatitis also may present findings of malignancy, such as the double duct sign, ductal strictures, and infiltration of adjacent fat. Although there are some differential features in image findings such as 


\section{Case Reports in Gastroenterology}

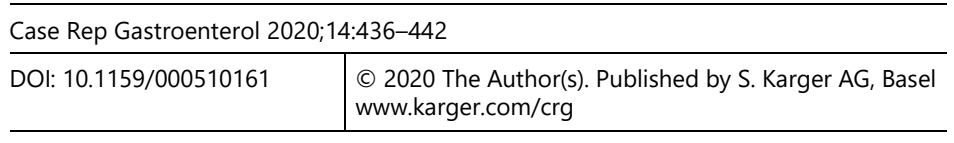

Heo: Infected Pancreatic Necrosis Mimicking Pancreatic Cancer

calcification inside the mass, "duct-penetrating sign," and an abrupt interruption of a smoothly dilated pancreatic duct with upstream pancreatic atrophy [1], these are not always present, as in the case reported herein.

In cases of clinically suspected pancreatic cancer that is at an operable stage, surgical resection might be preferred in the absence of any other invasive pathologic diagnosis. However, in clinical practice, there is the possibility of misdiagnosis and subsequent unnecessary surgical resection for benign pancreatic disease. It was known that benign pancreatic disease accounts for 5-21\% of all pancreatectomy-presumed cancers [3, 4]. Several case reports on pancreatic abscesses (infected pancreatic necrosis) have been published that would come close to misdiagnosis as malignancy. These lesions were finally diagnosed based on diagnostic laparoscopy, CT-guided percutaneous aspiration, and EUS-FNA (Table 1) [5-8]. Among these modalities, EUS with FNA has an advantage because it is less invasive in diagnosing pancreatic disease. It has also shown a higher diagnostic yield for indeterminate pancreatic masses compared with multidynamic CT [9]. In addition, EUS-FNA is used not only for diagnosis but also as a useful treatment modality for infected pancreatic necrosis. In general, drainage catheter placement is usually needed in addition to antibiotic treatment. However, if the amount of abscess aspirate is sufficient to minimize the abscess cavity, drainage with aspiration only might be sufficient for treatment [10].

Infected pancreatic necrosis may be present and can be confused with pancreatic malignancy in an early stage of development. Therefore, awareness of the natural course of pancreatitis and infection/abscess formation is important. In addition, EUS-FNA should be recommended for the diagnosis and treatment of indeterminate pancreatic lesions in selected patients.

\section{Statement of Ethics}

I have reported this case in compliance with the Declaration of Helsinki. Consent was obtained from the patient for publication of the clinical data.

\section{Disclosure Statement}

I have no conflicts of interest to disclose.

\section{Funding Sources}

No funding was obtained for this study. 


\section{Case Reports in Gastroenterology}

Case Rep Gastroenterol 2020;14:436-442

\section{References}

1 Torres US, Matsumoto C, de Macedo Neto AC, Caldana RP, Motoyama Caiado AH, Tiferes DA, et al. Common and Uncommon Benign Pancreatic Lesions Mimicking Malignancy: Imaging Update and Review. Semin Ultrasound CT MR. 2018 Apr;39(2):206-19.

2 Trikudanathan G, Wolbrink DRJ, van Santvoort HC, Mallery S, Freeman M, Besselink MG. Current Concepts in Severe Acute and Necrotizing Pancreatitis: An Evidence-Based Approach. Gastroenterology. 2019 May;156(7):1994-2007.e3.

3 Gerritsen A, Molenaar IQ, Bollen TL, Nio CY, Dijkgraaf MG, van Santvoort HC, et al.; Dutch Pancreatic Cancer Group. Preoperative characteristics of patients with presumed pancreatic cancer but ultimately benign disease: a multicenter series of 344 pancreatoduodenectomies. Ann Surg Oncol. 2014 Nov;21(12):39994006.

4 Birnbaum DJ, Gaujoux S, Berbis J, Dokmak S, Hammel P, Vullierme MP, et al. Surgery for pancreatic neoplasms: how accurate are our surgical indications? Surgery. 2017 Jul;162(1):112-9.

5 Chase MP, Yarze JC, Gumustop B, Leach RP. Endoscopic ultrasound-guided aspiration and oral antibiotic therapy as definitive treatment of an asymptomatic pancreatic abscess. Pancreas. 2009 May;38(4):475-6.

6 Chong VH. Isolated pyogenic pancreatic abscess mimicking a neoplasm. JOP. 2008 May;9(3):309-12.

7 Shulik O, Cavanagh Y, Grossman M. Pancreatic Lesion: malignancy or Abscess? Am J Case Rep. 2016 May;17:337-9.

8 Kim MJ, Seo EK, Kang ES, Kim KM, Oh YM, Cho BH, et al. Pyogenic pancreatic abscess mimicking pancreatic neoplasm: a four-case series. Korean J Gastroenterol. 2015 Apr;65(4):252-7.

9 Krishna SG, Rao BB, Ugbarugba E, Shah ZK, Blaszczak A, Hinton A, et al. Diagnostic performance of endoscopic ultrasound for detection of pancreatic malignancy following an indeterminate multidetector CT scan: a systemic review and meta-analysis. Surg Endosc. 2017 Nov;31(11):4558-67.

10 Jo HG, Amarbat B, Jeong JW, Song HY, Song SR, Kim TH. Could Transgastric Endoscopic Ultrasound-Guided Aspiration Alone Be Effective for the Treatment of Pancreatic Abscesses? Clin Endosc. 2015 Jul;48(4):345-7. 


\section{Case Reports in Gastroenterology}

Case Rep Gastroenterol 2020;14:436-442

DOI: $10.1159 / 00051016$

(c) 2020 The Author(s). Published by S. Karger AG, Basel www.karger.com/crg

Heo: Infected Pancreatic Necrosis Mimicking Pancreatic Cancer
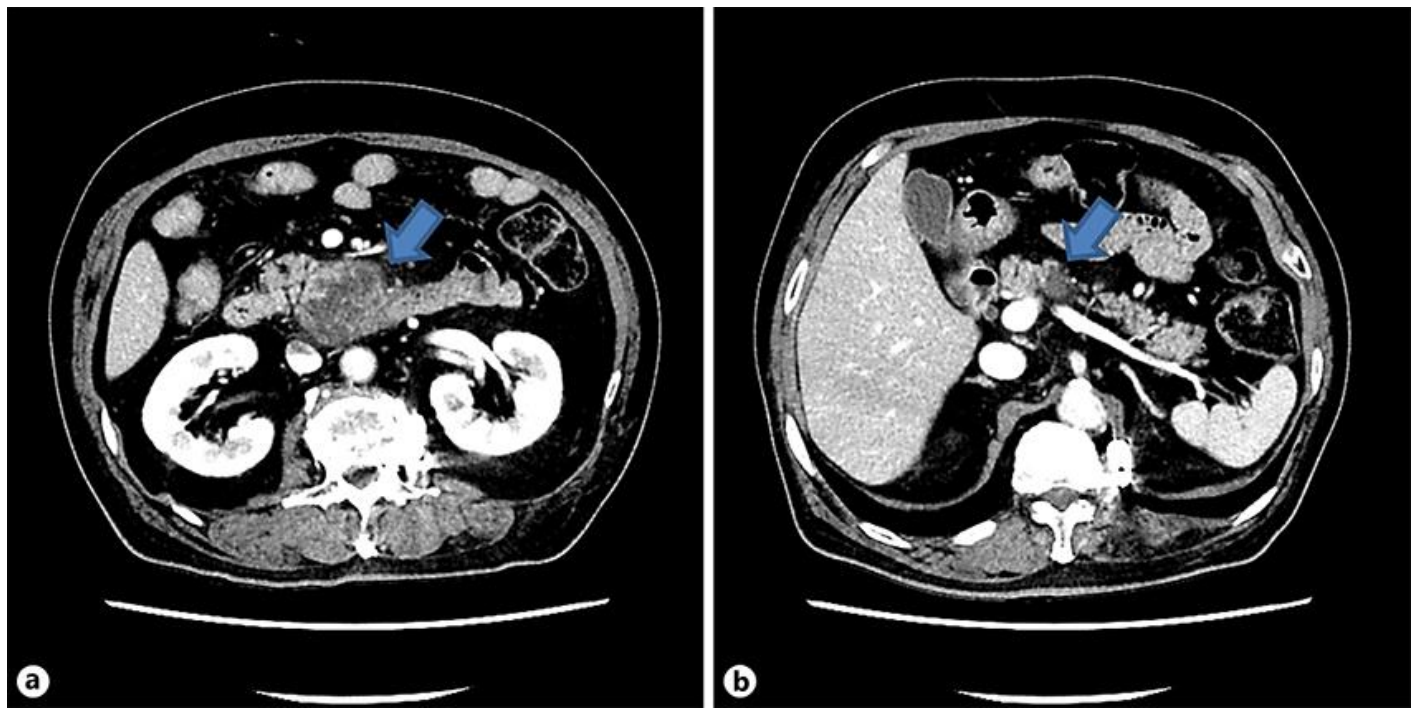

Fig. 1. Abdominal CT. a $53 \times 39 \mathrm{~mm}$, heterogeneously enhancing, low-attenuating mass in the pancreatic uncinate process (arrow). b $19 \times 14 \mathrm{~cm}$, heterogeneously enhancing, low-attenuating mass in the pancreatic body (arrow).
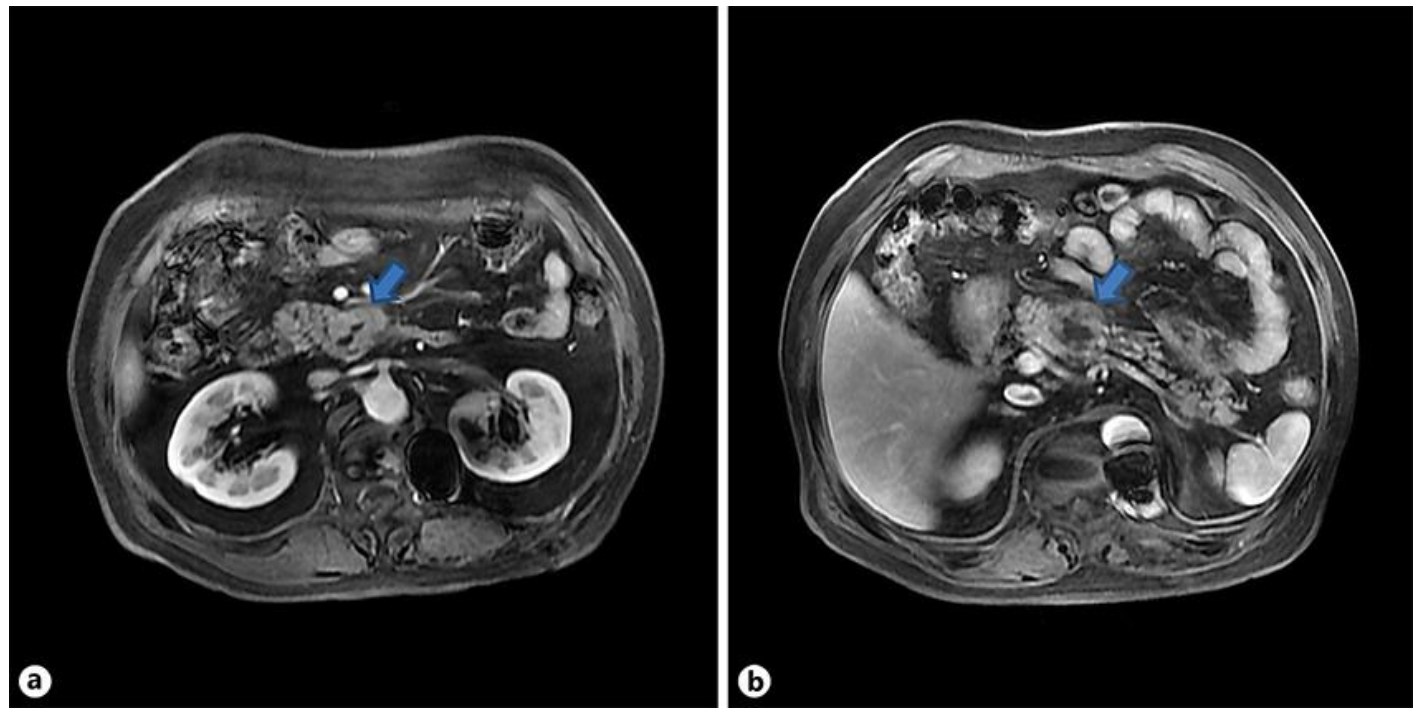

Fig. 2. Liver acquisition with volume acceleration dynamic image (MRI). Peripheral enhancement was also observed in the pancreatic masses. a The mass in the uncinate process decreased from 53 to $35 \mathrm{~mm}$ (arrow). $\mathbf{b}$ The mass in the body increased from 19 to $40 \mathrm{~mm}$ (arrow). 
Case Reports in
Gastroenterology

Case Rep Gastroenterol 2020;14:436-442

(C) 2020 The Author(s). Published by S. Karger AG, Basel www.karger.com/crg

Heo: Infected Pancreatic Necrosis Mimicking Pancreatic Cancer

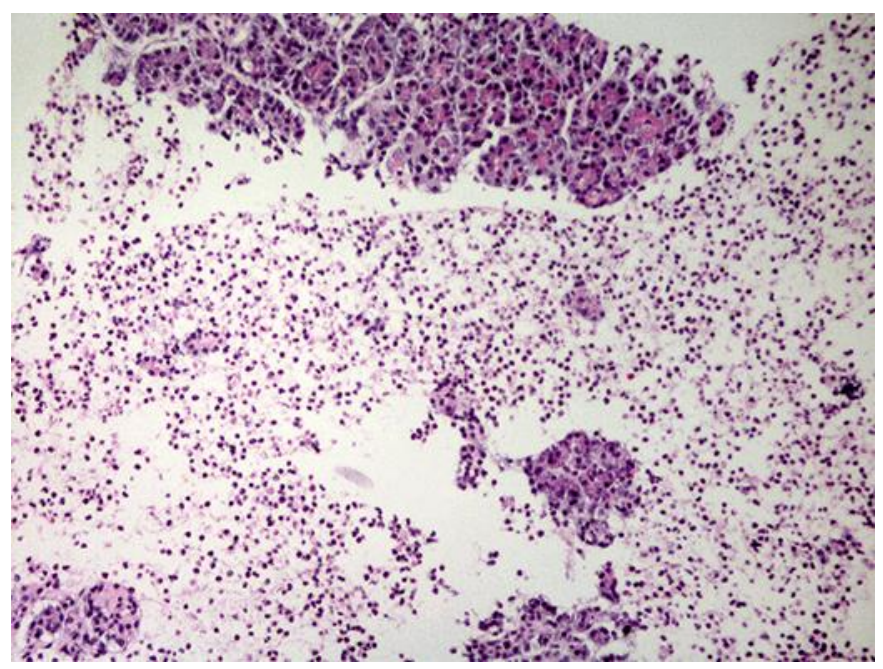

Fig. 3. Microscopic examination. Diffuse neutrophil and lymphocyte infiltration near the pancreatic parenchyma (H\&E stain. $\times 200)$.

Table 1. Review of published cases of pancreatic abscesses (infected pancreatic necrosis) mimicking pancreatic cancer

\begin{tabular}{|c|c|c|c|c|c|c|c|c|}
\hline $\begin{array}{l}\text { First author [ref.], } \\
\text { year }\end{array}$ & $\begin{array}{l}\text { Age, } \\
\text { years/ } \\
\text { Sex }\end{array}$ & Symptoms & Location & Fever & $\mathrm{WBC} / \mu \mathrm{L}$ & Size, cm & Comorbidities & $\begin{array}{l}\text { Diagnostic } \\
\text { modality }\end{array}$ \\
\hline Chase [5], 2009 & $48 / \mathrm{M}$ & None & $\begin{array}{l}\text { Body and } \\
\text { tail }\end{array}$ & No & n.a. & $8.0 \times 10.0$ & DM, alcoholics & EUS-FNA \\
\hline Shulik [7], 2016 & $67 / \mathrm{M}$ & Jaundice & Head & No & $\begin{array}{l}\text { Within } \\
\text { normal limits }\end{array}$ & $3.1 \times 2.4$ & DM & EUS-FNA \\
\hline Chong [6], 2008 & $72 / \mathrm{M}$ & $\begin{array}{l}\text { Abdominal } \\
\text { discomfort }\end{array}$ & Head & No & n.a. & 3 & $\mathrm{DM}$ & $\begin{array}{l}\text { CT-guided } \\
\text { percutaneous } \\
\text { aspiration }\end{array}$ \\
\hline Kim [8], 2015 & $51 / \mathrm{F}$ & $\begin{array}{l}\text { Abdominal } \\
\text { pain }\end{array}$ & Body & No & 9,100 & 2.7 & $\mathrm{DM}$ & Laparoscopy \\
\hline This case, 2020 & $67 / \mathrm{M}$ & $\begin{array}{l}\text { Body weight } \\
\text { loss }\end{array}$ & $\begin{array}{l}\text { Body and } \\
\text { uncinate } \\
\text { process }\end{array}$ & No & 7,060 & 5 and 2 & DM, alcoholics & EUS-FNA \\
\hline
\end{tabular}

DM, diabetes mellitus; EUS-FNA, endoscopic ultrasound-guided fine-needle aspiration. 